\title{
Os movimentos sociais e a luta pelo direito à cidade no Brasil contemporâneo
}

\author{
The social movements and the struggle for \\ the right to the cityin contemporary Brazil
}

\author{
Maria Clariça Ribeiro Guimarães \\ Professora do curso de Serviço Social da Universidade Federal de Campina Grande (UFCG)/PB, \\ Brasil; vice-líder do Grupo de Estudos e Pesquisas Marxistas em Serviço Social (Gepemss). \\ clarica.ribeiro@gmail.com
}

\begin{abstract}
Resumo: Na medida em que a expansão das cidades ocorre cada vez mais empurrando e segregando a classe trabalhadora para as áreas periféricas, destituídas de serviços e de infraestrutura, o espaço urbano se constitui também como um local importante na luta de classe. Nesse sentido, o presente artigo visa analisar a organização política dos movimentos sociais urbanos na contemporaneidade, nos seus processos de luta por direitos sociais, com ênfase no direito à cidade.
\end{abstract}

Palavras-chave: Cidades. Luta de classe. Movimentos sociais.

\begin{abstract}
As the expansion of the cities occurs more and more in such a way as to push the working class to (and to segregate it in) peripheral areas without any services and infrastructure, the urban space is also an important space in the working class struggle. So, this article aims at analyzing the political organization of the urban social movements nowadays: their processes of struggle for social rights, with an emphasis on the right to the city.
\end{abstract}

Keywords: Cities. Working class struggle. Social movements.

\section{Introdução}

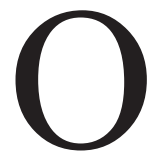

urbano consiste em um dos espaços que tem se revelado de importância fundamental para a luta de classes nas últimas décadas. Ao expandirem-se empurrando segmentos das classes subalternas para as áreas periféricas, destituídas de serviços, de infraestrutura urbana e de equipamentos coletivos, as cidades brasileiras têm se configurado como 
espaço de grande segregação socioespacial. A dinâmica de produção e de reprodução do espaço não pode ser pensada excetuada de sua intrínseca relação com os processos de acumulação capitalista e de exploração da força de trabalho, assim como também tal reflexão não pode estar apartada das lutas e resistências populares engendradas nesse contexto.

Nesse sentido, no presente artigo evidenciamos a ação política dos movimentos urbanos que atuam na luta pelo reconhecimento e garantia do direito à cidade, apreendendo avanços e entraves em seus processos de organização e mobilização. A análise aqui tecida acompanha e se fundamenta em um amplo debate acerca das tendências postas à organização popular na contemporaneidade. Para tanto, caracterizamos a ação política dos movimentos sociais urbanos na luta pelo reconhecimento e garantia de direitos sociais, com ênfase no direito à cidade. A partir desse enfoque, discutimos os avanços/conquistas e dificuldades/entraves encontrados pelos movimentos na intervenção em face da questão urbana brasileira.

Problematizamos, ainda, os desafios postos para os movimentos sociais e centramos nossa discussão em torno das estratégias adotadas por estes, seus processos de organização e mobilização, evidenciando dilemas e contradições que perpassam suas lutas no período contemporâneo, dimensões importantes para a análise da ação política.

\section{Estratégias de organização e mobilização}

A classe trabalhadora vive no cotidiano de sua existência a miséria gerada pelo capitalismo dependente, expressa na concentração fundiária, na superexploração, na falta de acesso a direitos humanos e sociais básicos, entre tantos outros aspectos. É partindo das contradições reais vivenciadas pela classe trabalhadora que se constrói uma plataforma de mudanças e bandeiras de luta. Daí a importância de situarmos as estratégias dos movimentos sociais no contexto de luta pela hegemonia, questão central quando nos referimos ao processo de organização e mobilização popular. Significa, por um lado, o processo de empreender a crítica teórica e prática à 
dominação capitalista e, por outro, construir as possibilidades de alteração dessa realidade.

Nesse sentido de construção da hegemonia, no seio da luta política, estratégias como ocupação/acampamento foram sendo construídas como ações intrínsecas à atuação política desses movimentos, a partir da realização de discussões periódicas nas comunidades sobre a situação daqueles que não possuem casas, seguidas de levantamento das pessoas dispostas a integrar e realizar a ocupação, isto é, concordando em ocupar e acampar, literalmente, em alguma área da cidade como meio de pressionar e agilizar a conquista de moradias.

O momento do acampamento tende a constituir a ocasião na qual as discussões políticas mais específicas das propostas do movimento são travadas. Os barracos de lona preta, moradia por tempo incerto e provisório, são fixados no período da ocupação, juntamente com as bandeiras e simbologias da luta, deixando espaço reservado para as assembleias do movimento, nas quais são debatidos os próximos passos a serem dados, incluindo as questões do acampamento, em especial no que diz respeito à distribuição de tarefas. Afinal, a necessidade de organização do acampamento apresenta novas exigências e demandas internas para o movimento e para o processo de organização das famílias.

Diante das comparações passíveis de serem feitas entre as estratégias de luta adotadas pelos movimentos sociais urbanos e aquelas impulsionadas pelos movimentos do campo, dentre os quais o Movimento dos Trabalhadores Rurais Sem Terra (MST), afirmamos que a relação entre a ação política de ambos os movimentos não se restringe apenas ao uso de uma estratégia comum, e isto fazemos questão de enfatizar. Trata-se, na realidade, de uma relação bem mais profunda, na medida em que constitui uma relação estrutural, entendida dessa forma porque em momento algum perdemos do horizonte a estreita vinculação entre campo e cidade.

Nesse sentido, a reforma agrária - principal bandeira que move as reivindicações dos sem-terra - revela-se como uma dimensão da questão também urbana; quiçá seja a reforma agrária a principal questão urbana 
(Silva, 1996), ou seja, componente fundamental da reforma urbana e da materialização do direito à cidade. Nessa perspectiva, a respeito da legitimidade da estratégia de ocupação, José Gomes da Silva, ex-presidente do Instituto Nacional de Colonização e Reforma Agrária (Incra), assevera:

As ocupações existem porque, no contexto social que vivenciamos, o ocupante procura por trabalhos em espaços vazios, abandonados, sem destinação, empurrado pela necessidade de fome, de trabalho, como imperativo de emergência. Assim, em razão de ser famélica esta ocupação, ela não pode ser punível. Ocupar terra para plantio [e para moradia] não é delito; delito é o estoque especulativo de terras. Merecem punição, de acordo com a lei, os proprietários que mantêm a terra ociosa, sem destinação social. (Silva, 1996, p. 2)

Duas preocupações aparecem implícitas na nota supracitada: insistir na defesa das ações do movimento, reafirmando a legitimidade da estratégia de ocupação, e demarcar enfaticamente uma diferença radical entre ocupação e invasão. Essa preocupação em diferenciar bem essas duas noções decorre especialmente do fato de invasão ser tipificada no Código Penal como "esbulho possessório visando à obtenção de vantagens econômicas ou financeiras", não correspondendo, portanto, de forma alguma ao que fazem os movimentos sociais urbanos e rurais.

Dada a imensa desigualdade socioespacial, geradora também de significativa quantidade de pessoas despejadas de seus territórios de moradia, não resta a essas famílias nenhuma alternativa legal a não ser a estratégia legítima de ocupação da terra para morar. Mas nesse percurso entre a ilegalidade e a legitimidade da ocupação, novas formas e conteúdos de segregação socioespacial também vão se consolidando, sob a marca de uma onda de larga estigmatização da pobreza urbana, via ampla disseminação da "cultura do medo" e consequente isolamento da elite em verdadeiros guetos de luxo.

Nada mais do que um reforço à dualidade entre cidade dos ricos e cidade dos pobres, ou mesmo entre cidade legal e cidade ilegal (Bonduki, 2010), aprofundando as contradições e os desdobramentos da questão social na atualidade, bem como a criminalização da pobreza com base na noção 
de "classe perigosa". Aqui, cabe atentar para o alerta de Ermínia Maricato (2011) sobre a ilegalidade da propriedade da terra urbana não se referir somente aos pobres, haja vista serem também ilegais os loteamentos fechados — alguns bastante famosos — que se multiplicam nos arredores das grandes cidades, na proporção em que estes usufruem privadamente de áreas verdes e também vias fechadas de trânsito intramuros.

Outrossim, impera no cotidiano da atuação política dos movimentos sociais o largo quadro de dificuldades contemporâneas de organização e mobilização das massas, adensado em um cenário de ampliação do desemprego, precarização do trabalho e agravamento da pobreza. Por certo, reconhecemos que a realidade está prenhe de focos de resistência classista, com diversos sujeitos coletivos empreendendo lutas concretas em prol dos interesses das classes subalternas. Todavia, não podemos negar que, nas últimas décadas, as transformações ocorridas no mundo do trabalho e na dinâmica de produção capitalista operaram alterações substantivas no seio da classe trabalhadora e produziram um cenário de inúmeras dificuldades para a organização política crítica e combativa.

Reaparecem, na contemporaneidade, preocupações antigas e bastante caras aos movimentos urbanos no que diz respeito a participação, organização, mobilização e conscientização, conforme atestam os debates realizados nos Encontros de Movimentos Populares, sistematizados por Ana Maria Doimo (1984, p. 37):

a) há muita dificuldade em mobilizar a população. É preciso descobrir meios para motivar a participação; b) há falta de líderes e os que existem têm muitos compromissos assumidos; c) a televisão é a maior rival; d) faltam recursos financeiros para o incremento de meios de divulgação e mobilização. Por outro lado, os meios de comunicação pouco apoio dão; e) a investida do poder público é muito grande e a maneira como ele se apresenta torna difícil entender se ele é adversário ou protetor; f) as pessoas querem resultado a curto prazo e não têm um objetivo maior para lutar; g) o povo não acredita na sua força e nem na política; h) é preciso integrar mais os movimentos de bairro e não ficar só a nível das reivindicações, mas promover o lazer e a cultura (teatro, cineclube etc.). 
Verificamos com isso que preocupações da década de 1980 permanecem na ordem do dia no que se refere à ação política dos movimentos populares urbanos no período recente. Entendemos que dois aspectos são especialmente centrais para engendrar e atualizar de modo permanente tais dificuldades de mobilização, a saber: o peso da formação sócio-histórica brasileira e, nos dizeres de Ivo Tonet (2009), as expressões socioculturais da crise capitalista na atualidade, que traz como uma de suas manifestações o alargamento da ideologia individualista.

Com efeito, marcas de nossa herança colonial se atualizam e se transformam ao mesmo tempo, se reapresentando sob novas condições históricas e produzindo novos elementos para pensarmos os processos político-organizativos contemporâneos. Nesse contexto, como assinala Iamamoto (2011), o desafio é compreender o modo como o capital articula essa multiplicidade de relações, trazendo para as determinações do tempo presente a incorporação de outras tantas diferentes lógicas e relações que produziu no passado.

Essas considerações parecem-nos imprescindíveis a qualquer abordagem teórico-metodológica coerente com a perspectiva de totalidade, pois, sem dúvida, a particularidade do desenvolvimento brasileiro repercute em diversas outras dimensões da realidade atual, mais ainda na forma como os movimentos sociais se organizam no país.

Sabemos que o desenvolvimento capitalista brasileiro foi conduzido de forma elitista e antipopular, marcado por apoios e negociações entre as classes dominantes, que, estrategicamente, antecipavam as reivindicações da classe trabalhadora ou, dependendo da conjuntura, recorriam à repressão via Estado, como se verifica no caso da prática dos golpes de Estado. Importa, sob a ótica da classe dominante, pacificar a classe trabalhadora e evitar grandes pressões populares em direção a uma ruptura radical com a ordem vigente. Prova disso é que "todas as opções concretas enfrentadas pelo Brasil, direta ou indiretamente ligadas à transição para o capitalismo (desde a independência política ao golpe de 1964, passando pela proclamação da República e pela Revolução de 1930), encontraram uma solução pelo alto" (Coutinho, 1988, p. 106-107). 
Vale ressaltar que Carlos Nelson Coutinho (1988) chama de "solução pelo alto" o fato de historicamente os rumos dos processos políticos no país serem resultado da conciliação entre as frações das classes economicamente dominantes, em vez de serem resultado de movimentos verdadeiramente populares, o que não significa ausência de reivindicações, protestos e lutas das forças democráticas.

Em linhas gerais, fica evidente na leitura do autor o quanto a noção de "revolução passiva", problematizada tanto por Florestan Fernandes quanto por Gramsci, constitui pressuposto indispensável para a construção de uma “imagem do Brasil" (Coutinho, 2013), isto é, de uma formulação não restrita à determinada questão específica da vida social do país. Se é verdade que nas elaborações de Gramsci encontramos apenas breves referências literais ao Brasil, também é inegável a contribuição ao entendimento da realidade brasileira fornecida pelas categorias teórico-analíticas com as quais o marxista italiano trabalha.

Em Florestan Fernandes (2005), contudo, a "imagem do Brasil” aparece de forma ainda mais explícita e sob uma ótica fundamentalmente marxista e revolucionária. A rigor, sua obra articula passado, presente e futuro ao processo de apreensão da sociedade e da vida política brasileira, contribuindo para uma leitura acertada e atual do movimento do real em curso. Presumimos assim ser o seu pensamento uma bússola indispensável para todo aquele que, em uma perspectiva marxista, opte por dedicar-se à compreensão e ao enfrentamento dos dilemas postos à revolução brasileira.

É evidente que a própria dinâmica da sociabilidade do capital é determinante, muitas vezes, para a geração de processos de acomodação à ordem - amparados na apatia e no imobilismo —, e entender essa dinâmica contribui para compreendermos o porquê da expressiva quantidade de sujeitos que não se inserem ou participam de algum espaço político e tampouco acreditam nas possibilidades da organização coletiva, atitudes extremamente difundidas pela lógica dessa sociabilidade.

À mobilização, entretanto, precede trabalho de base contínuo, pois embora aparentemente — dadas suas péssimas condições de vida — possamos 
logo pensar que o morador vai se envolver em qualquer tipo de luta, visto não ter nada a perder, não é de modo tão mecânico e imediato que esse processo se delineia. Predominantemente, é tão grande o seu nível de desilusão, medo e descrédito diante de todas as agruras vividas, que para ele parece indiferente qualquer ação. À medida que vai sendo chamado, ele vai se recusando; certo dia, acaba indo a uma das reuniões ou a alguma manifestação pública e termina se envolvendo (Silva, 1992).

Logo, para mobilizar para as lutas, o movimento necessita que seus militantes estejam cotidianamente trabalhando junto às bases e mostrando aos sujeitos os desafios e perspectivas das lutas. Trabalho de base, compreendido aqui como o desafio de despertar nos indivíduos o encanto pelo movimento político, com esperança na organização coletiva e na possibilidade de construção de ações políticas democráticas.

Percebemos, assim, ser o trabalho de base visualizado pelos movimentos sociais como uma das melhores formas de comunicar às pessoas o projeto político e a concepção de mundo que orienta a ação do movimento. Tomado concretamente, o trabalho de base assume diferentes formas, dependendo do setor ou segmento da sociedade com o qual o movimento está lidando, mas em todos os casos pressupõe a necessidade de traçar pontes de diálogo e conversação entre o movimento e aqueles sujeitos que potencialmente constituem seu alicerce.

Fundamental para o processo de mobilização popular, o trabalho de base revela-se também como uma estratégia importante para a luta política, em que pesem as diferentes perspectivas e métodos a partir dos quais pode vir a ser materializado. Trabalho popular que possui caráter educativo, revelando-se fundamental no processo de sensibilização para as lutas, como ressalta Peloso (2009, p. 49): “Quando se fala que em um lugar tem trabalho de base se está dizendo que ali há o surgimento de novos militantes, à altura, para dirigir uma parte, um setor ou uma luta dos trabalhadores".

Desse modo, evidencia-se nitidamente outra dimensão presente no trabalho de base: seu caráter formador de quadros para os movimentos. Afinal, para que os movimentos não percam sua capacidade de mobilização para as lutas, a formação política de seus militantes revela-se fundamental. 


\section{Avanços e entraves no cotidiano das lutas}

Sabemos que incidir na luta de classes em favor dos interesses do trabalho requer capacidade de conquistas e vitórias, mas também, muitas vezes, os movimentos se defrontam com derrotas e entraves. Historicamente, as reivindicações do movimento popular — ao proclamarem sua luta de forma aberta - têm como primeiro interlocutor as estruturas governamentais, na condição de formuladoras e implementadoras de políticas públicas, sendo muitos os dilemas e desafios que permeiam essa interlocução com o poder público.

Talvez a relação estabelecida com o Estado sempre tenha variado, entre outros fatores, em função dos objetivos estratégicos dos próprios movimentos (Gohn, 2007) e das condições em que operam os processos de negociação, da correlação de forças, entre outros aspectos.

Indubitavelmente, relaciona-se também às diferentes configurações assumidas pelo Estado no devir histórico, de onde decorre apenas ser possível entender o Estado - transvertido de poder público - pelas suas interdependências, em especial as que mantêm com a sociedade, haja vista essa ser o seu principal oposto, mas também principal termo de complementação (Ianni, 1986).

Daí a necessidade de superação dialética de uma concepção restrita de Estado e a formulação de novo conceito capaz de contemplar as exigências postas pelo movimento do real, como nos indica Coutinho (1987). Consideramos que a noção de Estado ampliado cunhada por Gramsci nos permite uma análise da dinâmica do real na qual se articula economia (domínio crescente do capital) e política (espaço legítimo de luta).

Exatamente por isso,

cuando hay oposición entre Estado y sociedad civil se trata más de una oposición entre proyectos e intereses organizados disímiles y no de esferas o ámbitos de vida de la sociedad — la sociedad civil no es una esfera orgánicamente diferenciada del Estado. (Oliver, 2009, p. 103) 
Afinal, sob essa ótica, ambas são um espaço social organicamente integrado.

Nesse sentido, e no que concerne às conquistas coletivas dos movimentos urbanos, estas ora expressam demandas essencialmente jurídicas e institucionais, ora se confundem com os processos de luta gerados, ponto de encontro/confronto de interesses distintos e antagônicos na condução da política pública urbana.

Embora não tenham deixado de ocupar imóveis ociosos que descumprem a determinação constitucional de atendimento à função social da cidade e, ao mesmo tempo, continuem organizando amplas manifestações de rua, a lista de conquistas destacadas pelos movimentos urbanos possui caráter demasiadamente jurídico e institucional, de acordo com Maricato (2011). A pesquisadora contabiliza, entre as conquistas dos últimos 20 anos: alguns capítulos da Constituição Federal de 1988; a Lei n. 10.257/2001; o Estatuto da Cidade, em 2000; a Medida Provisória n. 2.220/2001; a criação do Ministério das Cidades, em 2003; um Programa Nacional de Regularização Fundiária inédito em nível federal, em 2003; o Conselho Nacional das Cidades, em 2004; a Lei Federal n. 11.445/2007, que institui o marco regulatório do Saneamento Ambiental; a Lei Federal n. 11.107, de 2005, dos Consórcios Públicos; a Lei Federal n. 11.124/2005, do Fundo Nacional de Habitação de Interesse Social; a instituição, em 2006, desse Fundo; a Campanha Nacional do Plano Diretor Participativo.

Incitando reflexões sobre os movimentos sociais urbanos, Maricato (2011) já alertava — com base na relação supracitada — para o quanto se tornou remota a possibilidade de os movimentos urbanos debaterem temas estruturais, em um contexto no qual a preocupação central tem sido a busca por melhores condições de vida.

Ora, não é fácil conciliar a urgência no atendimento às necessidades imediatas relacionadas à sobrevivência do núcleo familiar com a disposição e a disponibilidade para participar de lutas coletivas que podem demandar tempos mais largos. Ademais, também é bastante forte o apelo ao individualismo e às soluções isoladas em contraposição à construção de 
vias coletivas, o que constitui entraves à organização dos movimentos sociais urbanos.

Maricato (2011) preocupa-se ainda com a condução da luta política na proporção em que ela vem sendo cada vez mais impactada pela forte atração para o espaço institucional. A crítica da autora parece não se estruturar no sentido de ignorar a luta por espaços institucionais, seja pela via eleitoral ou por outra qualquer, mas como um indicativo da necessidade imperativa de atribuirmos à luta institucional sua devida dimensão.

Não há, em sua elaboração, uma negação do quanto as conquistas das reivindicações concretas imediatas constituem alimento essencial para qualquer movimento reivindicatório de massas. Ao contrário. Apenas reiteram a necessidade de entendermos o Estado em sua complexidade, especialmente considerando as marcas patrimonialistas e desiguais presentes e atuantes na sociedade brasileira.

Sintomático das contradições postas é o fato de, desde a aprovação da Constituição Federal em 1988, muitas legislações municipais terem entrado em vigor - até porque o Estatuto das Cidades determina a elaboração de planos diretores para municípios com 20 mil habitantes ou mais —, e são numerosos também os tratados e convenções assinados pelo governo do Brasil, muitos com força de lei. Todavia, prevalecem ainda imensas desigualdades socioambientais, particularmente a crise da moradia no país. Como explicar tanta sofisticação nos aparatos jurídicos e, ao mesmo tempo, todo esse descompasso com a realidade?

A função social da propriedade expressa na Constituição Federal e reforçada pelo estatuto da cidade, como condição sine qua non para a efetivação da função social da cidade e, logo, para que o direito à cidade se universalize, colide com o paradigma do direito à propriedade que deve ser assegurado pelo Estado; o primado do direito à propriedade no âmbito das sociedades capitalistas contrapõe-se a uma possível materialidade da função social da propriedade. Esta segue como horizonte de lutas para os trabalhadores, justamente aqueles moradores das cidades em condições precárias de moradia, que permite tensionar a ação do Estado com 
vista ao desenvolvimento de políticas urbanas e de moradia com dimensão social.

Adotamos ainda, como chave explicativa, a concepção de que o direito, na sociedade capitalista, atravessa diversas tensões e expressões contraditórias, pois é, por essência, necessariamente um direito de classe, apresentando, do mesmo modo, limites e potencialidades que podem ser definidos apenas no interior da luta de classes. Por isso mesmo, apesar de reconhecermos suas contradições, apostamos na luta por direitos como uma necessidade extremamente atual, no âmbito da qual os sujeitos coletivos podem se fortalecer.

Da mesma forma, sendo a posse ou propriedade expressão da conquista de uma posição na hierarquia urbana (Santos, 1987), não nos surpreende que dentre as principais conquistas apontadas pelos movimentos urbanos encontre-se frequentemente a referência aos conjuntos habitacionais, frutos de processos de ocupação e de luta coletiva, culminando com a construção de unidades habitacionais para as diversas famílias vinculadas aos movimentos.

A construção das casas, sem dúvida, materializa importante conquista na luta pelo direito à cidade, mas também suscita novos questionamentos na perspectiva de analisar os movimentos urbanos e a organização popular na sua dinâmica e contraditoriedade. Afinal, mais do que um ponto de chegada, a ocupação e sua posterior transformação em conjunto habitacional não consistiriam senão o início de novas experiências, sinalizando a partir daí para novas dimensões na trajetória de luta e de organização popular relativas à questão urbana?

Com infraestrutura básica e os serviços urbanos essenciais praticamente inexistentes, após algum tempo de permanência nos conjuntos habitacionais, a tendência maior tem sido a da não permanência de grande parte dos moradores e a tentativa de retorno às favelas de onde aquelas famílias são originárias, ou ainda a implantação em outras áreas de favelas mais bem localizadas. Afinal, não têm se verificado alterações significativas nas condições de vida e de trabalho desses sujeitos, decorrentes da mudança radical do local e do tipo de moradia. Ao contrário. 
Fecha-se, com isso, um verdadeiro círculo vicioso, que vai da favela ao conjunto habitacional e de volta à favela, em um percurso no qual o conjunto habitacional - fruto de intenso processo de luta e de mobilização — representa uma "área de passagem" ou "área de trânsito" (Valladares, 1980) na trajetória dessas famílias. Para muitos, a "solução" tem se revelado parcial, limitada e provisória.

Em tempos adversos para as lutas do trabalho em contraponto aos ditames do capital, os ganhos e avanços destacados pelos movimentos urbanos têm se caracterizado por ser muito mais de cunho político e ideológico (no sentido de avanço no processo de consciência coletiva e de disposição para organizar-se politicamente) do que propriamente concretos.

O lugar de destaque atribuído pelas lideranças dos movimentos sociais à incidência da organização popular no processo de construção e de reconstrução da consciência política indica o reconhecimento da natureza do avanço presente no cotidiano da ação política desses movimentos, aquilo que parte expressiva da literatura especializada tem denominado de caráter educativo dos movimentos sociais.

Como elucida Kowarick (1985), existe, nos chamados grupos populares, uma consciência crescente em construção, denominada pelo autor de desnaturalização dos problemas sociais. Tal desnaturalização pode ser identificada na medida em que as condições de vida e trabalho nas quais estão imersos os sujeitos que compõem tais grupos passam gradativamente a não ser mais vistas como advindas de fenômenos naturais.

Assim, a organização popular possibilita a esses sujeitos perceber origens e causas socioeconômicas e políticas para os problemas com os quais se deparam, embora muitas vezes esta não passe de uma consciência ainda fragmentada. O referido processo pedagógico tem "originado aquilo que se poderia chamar de campo incipiente de organização de reivindicações populares, onde a população se organiza por meios próprios, com recursos ditos informais que permitem a ela sobreviver nessas cidades" (Kowarick, 1985, p. 75).

Face a tais avanços e entraves presentes na ação política dos movimentos urbanos, no plano geral, não podemos olvidar que a luta pela hegemonia 
de um projeto societário crítico e radicalmente oposto a essa sociabilidade exige dos movimentos sociais a capacidade política de estabelecimento de alianças com outros sujeitos individuais e coletivos, mas também requer a capacidade de identificar os mecanismos de atuação dos seus opositores.

\section{Aliados e opositores no processo da ação política}

Articular e ampliar a luta pelo direito à cidade exige ações imediatas, mas também a capacidade política de estabelecimento de alianças dos movimentos urbanos com outros sujeitos individuais e coletivos, elemento fundamental na ação política dos movimentos sociais, abrindo os horizontes da luta por direitos em direção a lutas emancipatórias.

Afinal, a história dos movimentos sociais não compreende exclusivamente sua história interna. Nas palavras de Gramsci (1978, p. 24), um movimento social — ou qualquer grupo social que seja — "não é isolado; tem amigos, afins, adversários, inimigos". Mas, logicamente, uma dimensão histórica e conjuntural perpassa as articulações e alianças estabelecidas.

O reconhecimento da importância e da necessidade de articulação entre as lutas do movimento sindical e as lutas do movimento popular, na cidade e no campo, aparece documentado desde, pelo menos, o início dos anos 1980, tendo sido reafirmado repetidas vezes em encontros, assembleias e espaços diversos dos mais variados movimentos. Enunciada no âmbito da literatura especializada como "triangulação sindicato/fábrica/bairro" (Doimo, 1984), a busca de articulação entre o movimento operário e sindical com os movimentos urbanos e vice-versa constitui aspecto historicamente presente na configuração da luta de classes no Brasil.

Nesse sentido, o Documento de São Bernardo - construído por dirigentes sindicais e representantes de movimentos populares de diversos estados do Brasil em encontro realizado em Taboão da Serra (SP) — é bastante ilustrativo dessa preocupação, ao reforçar a necessidade de interligação do movimento sindical com outras organizações populares: 
a) Dentro do princípio de que o movimento sindical não deve isolar-se dos outros movimentos populares, mas considerar-se parte dele, existe a necessidade urgente de rompermos com preconceitos, tanto do movimento sindical como dos demais movimentos populares, difundidos pela ideologia dominante e que nada contribuem para a efetivação dessa interligação; b) Exercitar a solidariedade na cooperação mútua com os sindicatos, imprimindo e divulgando o material e a prática das organizações populares. Utilizar a imprensa sindical para divulgar as lutas que estão sendo travadas nos bairros, ao mesmo tempo em que, nos seus órgãos de divulgação, as organizações populares façam chegar até o bairro as lutas sindicais do momento, permitindo, dessa forma, que os trabalhadores que moram no bairro com as suas famílias participem das lutas das categorias; c) As bandeiras dos movimentos populares que visam a melhoria das condições de vida da população (saúde, habitação, educação, transporte etc.) também devem ser apoiados pelos sindicatos; d) Em resumo, que os sindicatos e os outros movimentos populares discutam permanentemente entre si todas as bandeiras comuns e formas de solidariedade. (Documento de São Bernardo, 1981, p. 4-5)

Assim, não restam dúvidas de que a articulação dos movimentos populares com outros movimentos sociais e organizações de esquerda mostra-se extremamente necessária, principalmente nesse contexto de grandes ofensivas do capital. As alianças entre os movimentos possibilitam um salto qualitativo em termos de avanços políticos quando se consegue efetuar uma verdadeira ruptura com o corporativismo, entendendo a importância de abranger também, nas lutas e pautas defendidas, os interesses de outros grupos e organizações da classe trabalhadora, fortalecendo uma luta unitária.

Entretanto, dois sujeitos coletivos tradicionalmente presentes nas articulações com os movimentos urbanos não têm sido mencionados como alianças importantes pelos documentos difundidos por parte dos movimentos urbanos, a exemplo da Igreja e/ou dos partidos políticos de esquerda, quando sabemos ser, na história recente, expressivo o envolvimento da Igreja Católica com os movimentos sociais do Brasil.

Envolvimento este tido como uma decorrência direta das novas modalidades de intervenção inspiradas nas Comunidades Eclesiais de Base (CEBs) 
da Igreja Católica e da base filosófica e ideológica da teologia da libertação, a "teologia do ponto de vista do oprimido" (Muraro, 1999, p. 187). Ainda que não seja menos verdadeiro que o envolvimento político de determinados setores da Igreja com a organização popular tenha sido uma resposta à proliferação junto aos setores populares tanto da umbanda e das seitas pentecostais, como ao espectro do comunismo, que colocava em risco seu "rebanho" (Singer e Brant, 1980).

Diante de distintos impasses e ambiguidades da relação da Igreja com os movimentos populares há, porém, quem suponha que "com o seu trabalho de base a Igreja estaria não só preparando o povo como força viva nos movimentos, mas, sobretudo, conferindo a ele o processo de tomada de decisões - de baixo para cima - , inaugurando uma nova fase no caráter dos movimentos sociais" (Doimo, 1984, p. 35), a partir do trabalho teórico, teleológico e político dos intelectuais orgânicos da "nova Igreja".

Destarte, entendemos também que a falta de referências mais explícitas aos partidos políticos como aliados importantes na luta pela transformação societária expressa a cultura política brasileira, na qual impera ainda uma visão negativa dos partidos, além de estar diretamente relacionada com a crise de representatividade dos partidos políticos da atualidade.

Pesquisas precedentes já identificaram como uma das tendências presentes nos discursos dos militantes de movimentos sociais a enorme resistência à presença dos partidos e a negação da necessidade de articulação com estes (cf. Guimarães, 2011; Santos, 1995). Tais discursos se baseiam em experiências de relações dos movimentos sociais com os partidos políticos de caráter instrumental, que, conforme Santos (1995, p. 55), se caracteriza por "uma supervalorização dos ensinamentos da vanguarda do partido, a ponto de minimizar as necessidades e reivindicações concretas dos MS".

Não obstante, dada a diversidade de movimentos sociais existentes, inclusive em relação às mesmas demandas, por apresentarem diferenciações internas entre si quanto à forma de organização e o projeto político, a construção da unidade tem se configurado uma das dificuldades mais frequentemente encontradas no âmbito da ação política. 
Mas sua necessidade e importância estão presentes no alerta de Rosa Luxemburgo, segundo o qual uma simples luta econômica por salários pode tomar proporções de um importante fenômeno político. Da mesma forma, a luta política pode potencializar a luta econômica, em um movimento de relação permanente entre ambas, resultante do fato de "as greves gerais em determinadas cidades, as pacíficas lutas salariais e os massacres nas ruas, as batalhas nas barricadas: todas se entrecruzam, correm paralelas, se encontram, se interpenetram e se superpõem" (Luxemburgo, 2005, p. 282), em contínuo movimento.

Além disso, também na concepção gramsciana de hegemonia, identificamos a preocupação expressa com essa questão, posto que Gramsci (1978) defende a denominada unidade sociocultural, através da qual seria solidificada em torno de um mesmo fim e idêntica concepção de mundo toda uma multiplicidade de vontades desagregadas. Esse seria, para o autor, o processo pelo qual o proletariado desenvolve a "vontade coletiva". Todavia, há para tanto um pressuposto: a construção da vontade coletiva é eminentemente política e, portanto, exige a formação de alianças, condição fundamental - quiçá decisiva - para a conquista da hegemonia do proletariado.

$\mathrm{Na}$ expressão do próprio Gramsci, “o proletariado pode se tornar classe dirigente e dominante na medida em que consegue criar um sistema de alianças de classe que lhe permita mobilizar contra o capitalismo e o Estado burguês a maioria da população trabalhadora" (Gramsci, 1977, p. 22; grifos nossos).

Os políticos, outrora figuras centrais no encaminhamento dos problemas urbanos, atualmente perdem sua posição de relevo, na medida em que os movimentos passam a se reconhecer como força social, colocando-os num plano secundário, isto é, na condição de elemento intermediário das reivindicações originárias dos bairros, embora não se possa ignorar a expressiva participação de políticos tradicionais, que funcionam como uma espécie de "protetores" das comunidades locais, onde possuem suas bases eleitorais (Silva, 1992). Assim sendo, a reivindicação popular, no território brasileiro, continua vindo à cena acompanhada da ação/articulação com um político local. 
Mas recorrer a articulações com os políticos tradicionais não tem sido impeditivo para que, paralelamente a isso, os movimentos sigam articulando e encaminhando suas reivindicações de forma autônoma, estabelecendo seus próprios planos de luta e de organização. Não se trata, desse modo, de retorno aos tempos em que os vínculos estabelecidos com os políticos locais eram sintomáticos de uma situação na qual tudo o que se aspirava alcançar era pela via da articulação com um vereador ou parlamentar. Com efeito, evidencia-se que muitos movimentos continuam percebendo essas figuras como canais de acesso aos órgãos públicos e às instâncias de poder do Estado, ${ }^{1}$ ainda que apostem em uma relação de autonomia ou que restrinjam tais articulações aos políticos por eles caracterizados como "comprometidos com as lutas populares" e, predominantemente, demonstrem resistência ao estabelecimento de qualquer relação. Prevalece, num e noutro caso, a recusa a um retorno do político tradicional como o dono do bairro, a única fala, a fala competente (Silva, Amorim e Montenegro, 1988). Nesse caso, especialmente por temer que o movimento se torne dependente e atrelado a essas figuras, bem como por entender que, em troca, tais políticos exigirão que o movimento comprometa os votos da sua militância.

Os núcleos, ocupações e conjuntos habitacionais constituem, sem dúvida, um campo extremamente propício para a demagogia eleitoreira e para as disputas por parte de diversos partidos institucionalizados, em especial porque nesses espaços urbanos, mais do que quaisquer outras áreas da cidade, espera-se encontrar determinado perfil de eleitor, com base em certa categoria de problemas urbanos. Problemas esses que os políticos tradicionais reiteradamente utilizam em suas propagandas eleitorais, com vista a ampliar suas relações com esses espaços e com os sujeitos que ali moram, usando o voto como moeda de troca para barganhar benefícios e serviços para a comunidade.

Isso não significa precisamente o desconhecimento por parte dos moradores do jogo político do qual estão sendo objeto, muitas vezes até mesmo

1. Argumenta-se, entre as razões para as organizações populares estabelecerem alianças com as lideranças da política institucional, o fato de elas facilitarem e agilizarem as soluções, conseguirem recursos, subsídios, melhorias. 
nele envolvendo-se propositadamente, como sintetiza Medina (1964, p. 88): "O eleitor diz que vai votar, mas não vota. O cabo eleitoral finge que acredita, mas não acredita. O candidato, pelo menos antes da eleição, embora já informado pelo cabo eleitoral, continua afirmando que conta com o apoio de todos", todos cúmplices de uma mesma simulação.

Com efeito, apesar de amplamente aclamada como "a festa da democracia", corroboramos com a posição segundo a qual a luta eleitoral é compreendida como uma tática, e não apenas como mera fórmula burocrática. Portanto, não está dado de imediato, na concepção por nós defendida, que todos os partidos, movimentos e organizações de esquerda devam dedicar-se a ela do mesmo modo e em toda e qualquer conjuntura sócio-histórica, considerando-se os limites postos para um real acúmulo de forças da classe trabalhadora na luta eleitoral. Assim, o horizonte central para esse momento permanece sendo a organização popular como mediação fundamental para a realização de uma transformação estrutural nessa sociedade.

Por sua vez, os opositores ao projeto político dos movimentos e organizações populares podem ser englobados nos mais diferentes movimentos e sujeitos que defendem um projeto de direita, atuando a serviço dos interesses do capital. Até porque, no Brasil contemporâneo, as forças de direita atuam em absoluta consonância com "a versão moderna das ideologias que alimentaram a perpetuação do poder das elites e das mentalidades conservadoras e antidemocráticas [...]. Representa hoje a consolidação de uma sociedade de apartação social” (Sader, 1995, p. 193).

Não sem razão, uma análise da ação política dos movimentos sociais em face do atual contexto pressupõe identificar os mecanismos engendrados pela atuação da direita brasileira na atualidade. Esta, além de permanecer atuante e com uma agenda própria em defesa dos privilégios e interesses das elites, tem não apenas operado na contramão da defesa de direitos sociais historicamente conquistados, como também investido, pesadamente, na criminalização dos movimentos sociais.

Ora, atualmente, a direita brasileira articula e combina muito bem formas de convencimento e apassivamento das pressões sociais com a 
truculência peculiar e histórica com a qual sempre tratou os interesses e os movimentos da classe trabalhadora. Essa realidade impõe, assim, imensos desafios para a articulação e a materialização das bandeiras de luta da classe trabalhadora, pois o esforço direitista é justamente na direção de invisibilizar e despolitizar contradições sociais e lutas políticas.

A criminalização dos movimentos sociais, reeditada e intensificada, em um contexto de ascensão dos setores conservadores e reacionários, adensa e torna mais agudos os impasses postos ao avanço das forças populares, nos levando a crer em uma reatualização das formas de dominação política historicamente empreendidas pelas oligarquias tão presentes e atuantes nas cidades brasileiras.

Por certo, antes as engrenagens constitutivas do jogo político das oligarquias do país para legitimar-se no poder reproduziram amplamente a subalternidade das classes populares. Essas se baseavam, em especial, na cooptação e no uso eleitoreiro de organizações populares. Nos anos 2000, acrescenta-se de forma mais nítida a esses mecanismos - ainda amplamente utilizados, como bem atesta a atuação dos modernos representantes dessas oligarquias nas cidades — o recurso largamente adotado de não apenas negar direitos via prestação de serviços precários, como também criminalizar aqueles sujeitos individuais e coletivos que se contrapõem a essa lógica através de suas organizações.

Contudo, não se trata de um simples retorno ao passado do tratamento da questão social como caso de polícia - e nisso temos acordo com Rodrigo Castelo (2009) - , embora esteja constatado o progressivo aumento do exercício da violência policial, militar e paramilitar na contenção das tensões sociopolíticas. O que temos é, na realidade, um novo padrão de intervenção na questão social, que, ao agregar elementos consensuais e coercitivos, hegemônicos e ditatoriais, não recorre apenas aos aparelhos policiais, mas também aos militares. Não se trata, nesse sentido, de nenhuma particularidade das lutas urbanas no Brasil, e sim de uma realidade expressa na organização popular latino-americana, o fato de estarmos diante de uma verdadeira militarização da questão social no continente, 
com os conflitos políticos sendo gradativamente deslocados para o plano militar, realidade a respeito da qual exemplos exaustivos podem ser encontrados em Castelo (2009).

Tendo em vista o poder de alcance da mídia, não somente como transmissora de informações, mas, sobretudo, na condição de formadora de opinião — dada sua ampla inserção no cotidiano dos indivíduos - , ficamos a interrogar em que medida esta influencia compreensões acerca da questão social e dos movimentos que a politizam e, subjacente a isso, até que ponto a mídia poderia ser situada como aliada e/ou opositora à ação política dos movimentos sociais. Os movimentos populares demonstram considerar a mídia um espaço importante para publicizar questões que lhe são caras. Intencionam utilizar o espaço da mídia para "mostrar o seu lado", contar a sua versão dos fatos e processos sociais e ao mesmo tempo questionar o papel do Estado na reprodução das desigualdades sociais. Contudo, encontram inúmeras dificuldades para se inserir nos meios tradicionais de comunicação existentes nas cidades, dado elucidativo do tratamento dado pela mídia aos movimentos sociais.

Constitui tendência nacional que vem historicamente se delineando, estando bastante explícita na contemporaneidade, "a concentração dos meios de comunicação nas mãos de empresários, dublês de políticos, e de algumas poucas famílias poderosas, os quais fazem desse ofício um negócio lucrativo" (Sales, 2007, p. 99), sem dúvida em detrimento de qualquer papel social e público que poderia cumprir.

As intervenções da mídia dominante, ao contrário do que muitos pensam e do que ela própria proclama, estão longe de ser neutras e imparciais. Desse modo, embora a mídia anuncie em muitos momentos as demandas sociais das classes pauperizadas, um exame mais apurado demonstra o quanto esta é perpassada pela ideologia das classes dominantes. Fragmentos e recortes da realidade são veiculados como sendo a totalidade do real, sob a ótica das elites políticas detentoras da mídia local, contribuindo também em muitos dos casos para a crimizalização dos movimentos.

Identificar aliados e opositores no processo da ação política empreendida pelos movimentos urbanos no Brasil contemporâneo nos remete a crer 
que se tomamos como horizonte o solo histórico no qual se processam as relações sociais concretas, teremos mais elementos para afirmar que direita e esquerda estão longe de poder assumir a forma de "dialetos de uma mesma língua". ${ }^{2}$ Ademais, em ambos os casos, permanece a existência de sujeitos sociais que as materializam a partir de interesses em disputa.

\section{Considerações finais}

Numa perspectiva radicalmente divergente da linha teórica pós-moderna e neoconservadora, nosso estudo evidenciou a fragilidade das assertivas que afirmam que os movimentos sociais da atualidade evitam confrontos com outros sujeitos e constroem sua ação política diluindo as fronteiras de classe, isto é, desconsiderando divergências em termos de projetos societários defendidos. Ao contrário, é verdadeiro afirmar que - dando por reconhecidas as imensas dificuldades de resistência enfrentadas pelos movimentos classistas - alguns movimentos sociais têm (re)inventado importantes formas de confronto.

Todavia, o fazer político na realidade brasileira e os conflitos de classe aqui gestados estão condicionados por um contexto nacional de "diminuição da pobreza com a manutenção da ordem”, isto é, sem confrontar os interesses do capital. Com isso, até se consegue em alguns momentos a atenuação de conflitos (e sua decorrente despolitização), o que se dá, todavia, à custa de um alargamento significativo do tempo necessário para arrefecimento da desigualdade social, fazendo com que esta decaia de modo substancialmente lento, sinalizando novos desafios postos à organização popular.

Diante das análises que nos esforçamos para tecer, nossa insistência é por reafirmar aquilo que, em nossa concepção, está longe de estar superado: a necessidade de refundar a esquerda para refundar o Brasil. Necessidade hoje ainda mais premente, na proporção em que diversas expressões da

2. Conclusão, do nosso ponto de vista bastante equivocada, a que chega parte da literatura especializada das ciências sociais. 
barbárie se manifestam acentuadamente e, nesse processo, a história transcorre, e nela a ação política dos movimentos vai se delineando.

\section{Recebido em 27/2/2015 - Aprovado em 22/7/2015}

\section{Referências bibliográficas}

BONDUKI, Nabil. Uma cidade aberta e segura. Disponível em: $<$ http://www.cartacapital.com.br/sociedade/uma-cidade-aberta-e-segura $>$. Acesso em: 20 ago. 2010.

CASTELO, Rodrigo. As encruzilhadas da América Latina e a militarização da "Questão Social”. Temporalis, Brasília, n. 18, 2009.

COUTINHO, Carlos Nelson. As categorias de Gramsci e a realidade brasileira. In: NOGUEIRA, M. A. Gramsci e a América Latina. Rio de Janeiro: Paz e Terra, 1988. . Dualidade de poderes. 2. ed. São Paulo: Brasiliense, 1987.

. Marxismo e "imagem do Brasil" em Florestan Fernandes. Disponível em: $<$ http://www.artnet.com.br/gramsci/arquiv54.htm>. Acesso em: 30 mar. 2013.

DOCUMENTO DE SÃO BERNARDO. Taboão da Serra. São Paulo, 1981. (Mimeo.) DOIMO, Ana Maria. Movimento social urbano, Igreja e participação popular. Petrópolis: Vozes, 1984.

FERNANDES, Florestan. A revolução burguesa no Brasil: ensaio de interpretação sociológica. São Paulo: Globo, 2005.

GOHN, Maria da Glória. Teorias dos movimentos sociais: paradigmas clássicos e contemporâneos. 6. ed. São Paulo: Loyola, 2007.

GRAMSCI, A. Alguns temas da questão meridional. Rio de Janeiro: Paz e Terra, 1987. (Temas de ciências humanas, v. I.)

. Concepção dialética da história. Tradução de Carlos Nelson Coutinho. 3. ed. Rio de Janeiro: Civilização Brasileira, 1978. 
GUIMARÃES, M. C. R. O desafio da relação com os partidos políticos. In:

Nosso sonho não faz silêncio: os desafios do Movimento Estudantil de Serviço Social. Mossoró: UERN, 2011. (Monografia.)

IAMAMOTO, Marilda. Serviço Social em tempo de capital fetiche: capital financeiro, trabalho e questão social. 5. ed. São Paulo: Cortez, 2011.

IANNI, Octavio. Classe e nação. Petrópolis: Vozes, 1986.

KOWARICK, Lúcio. O Estado e a participação popular. In: PREFEITURA DO MUNICÍPIO DE SÃO PAULO. América Latina: crise nas metrópoles. São Paulo: Sempla, 1985.

LUXEMBURGO, Rosa. Greve de massas, partidos e sindicatos. In: BOGO, Ademar (Org.). Teoria da organização política: escritos de Engels, Marx, Lenin, Rosa, Mao. São Paulo: Expressão Popular, 2005.

MARICATO, Ermínia. O impasse da política urbana no Brasil. Petrópolis: Vozes, 2011. MEDINA, C. A de. A favela e o demagogo. São Paulo: Livraria Martins Editora, 1964. MURARO, Rose Marie. Memórias de uma mulher impossível. Rio de Janeiro: Record/ Rosa dos Tempos, 1999.

OLIVER, Lúcio. El Estado ampliado en Brasil y México: radiografía del poder, las luchas ciudadanas y los movimientos sociales. México: Unam, Programa de Posgrado en Estudios Latino Americanos, 2009.

PELOSO, Ranulfo. Como fazer o trabalho de base e organização popular. Método de trabalho de base e organização popular. São Paulo, 2009. (Caderno de Formação, n. 38.)

SADER, Emir. O anjo torto: esquerda (e direita) no Brasil. São Paulo: Brasiliense, 1995.

SALES, Mione Apolinário. (In)visibilidade perversa: adolescentes infratores como metáfora da violência. São Paulo: Cortez, 2007.

SANTOS, Milton. Espaço do cidadão. São Paulo: Nobel, 1987.

SANTOS, Silvana Mara Morais dos. A dimensão política dos movimentos sociais: um estudo das representações dos dirigentes comunitários sobre a relação entre os movimentos sociais urbanos e os partidos políticos. Dissertação (Mestrado) — Universidade Federal de Pernambuco, Recife, 1995. 
SILVA, José Borzachiello da. Os incomodados não se retiram. Fortaleza: Multigraf Editora, 1992.

SILVA, José Gomes da. A reforma agrária brasileira na virada do milênio. São Paulo: Abra, 1996.

SILVA, N. M. da; AMORIM, M. M. da; MONTENEGRO, A. T. Movimento de bairro: repetição/invenção. Recife: Etapas, 1988.

SINGER, A.; BRANT, V. O povo em movimento. Petrópolis: Vozes, 1980.

TONET, Ivo. Expressões socioculturais da crise capitalista na atualidade. In: CFESS.

Serviço Social, direitos sociais e competências profissionais. Brasília: CFESS/Abepss, 2009.

VALLADARES, Lícia do Prado. Passa-se uma casa: análise do programa de remoção de favelas do Rio de Janeiro. 2. ed. Rio de Janeiro: Zahar, 1980. 